\title{
PERSPECTIVAS TEMPORALES Y ASPECTUALES EN LAS OBRAS NARRATIVAS DE GABRIEL GARCÍA MÁRQUEZ
}

En este artículo se presenta el uso de algunos recursos linguiísticos que sirven para señalar valores temporales y aspectuales en español con fines narrativos y estilísticos en dos obras de Gabriel García Márquez: en su primera novela La Hojarasca y en su novela más conocida Cien años de soledad.

\section{Marco linguiístico - teórico:}

Las perspectivas temporales y aspectuales en español se indican con varios recursos linguísticos. Los más conocidos son los tradicionalmente llamados tiempos verbales que, debido a la confusión a la que se presta el término tiempo, es mejor denominar paradigmas verbales. El término es más adecuado ya que estas formas verbales (paradigmas) no sirven únicamente para expresar el tiempo sino también otras perspectivas (aspectuales, modales, estilísticas, pragmáticas, etc). Además de los mencionados paradigmas verbales hay una serie de construcciones verbales denominadas perífrasis verbales que sirven también para indicar valores temporales y aspectuales.

En los textos narrativos de Gabriel García Márquez predominan los paradigmas de la esfera del pasado (la serie del pasado): el pluscuamperfecto (y el antepretérito) para la anterioridad, el pretérito simple como paradigma central, el imperfecto para la simultaneidad, el condicional simple y el condicional compuesto para la posterioridad. Los paradigmas de la esfera del presente, es decir, de la serie básica aparecen en los diálogos, monólogos interiores (en los discursos incluidos en el texto - discurso directo, discurso indirecto, discurso indirecto libre). ${ }^{1}$

1 Los conceptos de serie básica y serie del pasado son de T. Miklič (1994/I, p. 88 y 1994/II, p. 13). Son constelaciones de paradigmas verbales especializados. La serie básica tiene como paradigma central el presente, que se refiere a las acciones paralelas o simultáneas; el pretérito compuesto y el pretérito simple se refieren a diferentes grados de anterioridad; el futuro simple y el futuro compuesto a diferentes grados de posterioridad. La serie básica tiene un amplio campo de usos ya que se puede usar para cualquier esfera temporal (presente actual, presente habitual, futuro, pasado presente histórico, extratemporalidad). A las dos series pertenecen también los paradigmas indicadores de la modalidad. 
Entre los paradigmas de la serie del pasado hay dos oposiciones importantes.

1) La oposición pretérito simple : imperfecto no es temporal sino aspectual. Con los dos paradigmas verbales se expresan acciones ${ }^{2}$ que se encuentran en el ámbito del pasado del narrador/hablante. Con el pretérito simple se presenta la perspectiva global: el narrador abarca una acción en su totalidad, como un narrador omnisciente la observa desde el inicio hasta el final. Con el imperfecto la perspectiva es cursiva, el narrador no observa la acción desde fuera sino que cambia de posición y "se acerca" a la acción para ver solamente una parte de ella, no le interesa presentarla en su inicio y ni en su fin.

2) La oposición pretérito simple : pretérito compuesto ${ }^{3}$ puede ser temporal y/o aspectual. En el español de España es primordialmente temporal: el pretérito compuesto expresa una acción relacionada con el momento del habla (con el presente del hablante), el pretérito simple expresa una acción pasada, terminada, que no tiene relación con el presente del hablante. En el español de América el pretérito simple prevalece y desempeña también el papel del pretérito compuesto: la oposición temporal entre los dos paradigmas se neutraliza y desaparece. Sin embargo, permanecen dos oposiciones aspectuales entre los paradigmas mencionados: con el pretérito simple se indican acciones terminadas en el pasado remoto o cercano; con el pretérito compuesto se expresa, por una parte, el resultado de las acciones pasadas y, por otra parte, las acciones que duran y siguen desarrollándose en el momento del habla.

\section{La hojarasca}

Para Gabriel García Márquez el punto de partida de una obra es siempre una imagen visual. ${ }^{4}$ La Hojarasca, su primera novela injustamente considerada como una obra menor, es también una imagen, un solo instante captado e inmovilizado, el tiempo

2 En este estudio, si no se indica de otra manera, el término acción significa acción propiamente dicha, proceso y estado.

3 Se usan estos términos en lugar de las denominaciones tradicionales de pretérito indefinido y pretérito perfecto para caracterizar estas dos formas verbales por su forma y no por su contenido. Coincidimos con la opinión de $\mathbf{M}$. Skubic que respecto a este tema dice:

Con el fin de demarcar las concepciones de la forma y del contenido denominaré con el nombre de pretérito simple la formas "hice", etc., y con el del pretérito compuesto las formas "he hecho", etc. (Skubic, 1969, p. 1891)

$4 \quad$ - ¿Cuál es en tu caso, el punto de partida de un libro?

- Una imagen visual. En otros escritores, creo, un libro nace de una idea, de un concepto. Yo siempre parto de una imagen. "La siesta del martes", que considero mi mejor cuento, surgió de la visión de una mujer y una niña vestidas de negro y con un paraguas negro, caminando bajo un sol ardiente. "La Hojarasca" es un viejo que lleva a su nieto a un entierro. El punto de partida de "El Coronel no tiene quien le escriba" es la imagen de un hombre esperando una lancha en el mercado de Barranquilla. (Gabriel García Márquez, 1983, p. 26) 
y el espacio paralizados: un muerto en una habitación y varias personas en su alrededor velándolo. En La Hojarasca existe la sensación del tiempo que no avanza.

Pero entonces el niño vuelve a moverse y hay una nueva transformación en el tiempo. Mientras se mueva algo, puede saberse que el tiempo ha transcurrido. Antes no. Antes de que algo se mueva es el tiempo eterno, el sudor, la camisa babeando sobre el pellejo y el muerto insobornable y helado detrás de su lengua mordida. Por eso no transcurre el tiempo para el ahorcado: porque aunque la mano del niño se mueva, él no lo sabe. (LH, 43-44)

Un examen detenido del texto demuestra que hay varios "tiempos":

- El tiempo interior del espacio interior cerrado (la habitación) que se inmoviliza/eterniza en el momento cuando acaba la siesta. ${ }^{5}$ Es el lapso de tiempo entre las 2.30 y las 3 de la tarde del miércoles 12 de septiembre de 1928.

- El tiempo exterior, abierto. Es el tiempo que corre fuera de la habitación.

Los dos tiempos y espacios marchan a diferente ritmo.

Si el tiempo de adentro tuviera el mismo ritmo del de afuera, ahora estariamos a pleno sol, con el ataúd en la mitad de la calle. Afuera sería más tarde: sería de noche. Sería una pesada noche de septiembre con luna y mujeres sentadas en los patios, conversando bajo la claridad verde, y en la calle, nosotros, los tres renegados, a pleno sol de este septiembre sediento. ( $\mathrm{LH}, 42)$.

- Además de los tiempos delimitados por el marco de la habitación existe un tiempo interior, personal de cada protagonista que fluye a su manera y puede ser muy amplio ya que puede abarcar toda su vida, dilatarse hacia el pasado y prever el futuro.

En la introducción a la novela hay una voz colectiva (en la primera persona del plural) y tres voces (narradores) individuales, tres monólogos interiores de tres personajes que presentan tres visiones de una misma realidad, tres récits de una misma histoire. Algunos elementos vinculan los tres personajes (el niño, el abuelo y la madre) al mundo exterior y real: el pito del tren a las dos y media de la tarde, los alcaravanes, el calor, el olor. El ambiente es de una sofocación insostenible, claustrofóbica.

Las percepciones del espacio, la gente, los objetos y los acontecimientos en el momento cuando los protagonistas piensan y actúan (lo que coincide con el momento del monólogo interior) se expresan con los paradigmas verbales de la serie básica (LH 9-10, LH 20):

Siempre crei que los muertos debian tener sombrero. Ahora veo que no. Veo que tienen la cabeza acerada y un pañuelo amarrado en la mandibula. Veo que tienen la boca un poco abierta y que se ven detrás de los labios morados, los dientes manchados e irregulares. Veo que

5 El calor es sofocante en la pieza cerrada. Se oye el zumbido del sol por las calles, pero nada más. El aire es estancado, concreto: se tiene la impresión de que podria torcérsele como una lámina de acero. (LH, 9)

Hay un minuto en que se agota la siesta. Hasta la secreta, recóndita, minúscula actividad de los insectos cesa en ese instante preciso; el curso de la naturaleza se detiene; la creación tambalea al borde del caos y las mujeres se incorporan, babeando, con la flor de la almohada bordada en la mejilla, sofocadas por la temperatura y el rencor, y piensan: "Todavía es miércoles en Macondo". $(\mathrm{LH}, 42)$ 
tienen la lengua mordida a un lado, gruesa y pastosa, un poco más oscura que el color de la cara, que es como el de los dedos cuando se les aprieta con un cáñamo. Veo que tienen los ojos abiertos, mucho más que los de un hombre; ansiosos y desorbitados, y que la piel_parece ser de tierra apretada y húmeda. Creí que un muerto parecía una persona quieta y dormida y ahora veo que es todo lo contrario. Veo que parece una persona despierta y rabiosa después de una pelea. (LH, 9-10)

Examino la habitación y veo que se ha olvidado un zapato en la cama. Hago una nueva señal a mis hombres, con el zapato en la mano, y ellos vuelven a levantar la tapa en el preciso instante en que pita el tren, perdiéndose en la última vuelta del pueblo. $(L H, 20)$

La Hojarasca es una de las raras obras en que García Márquez emplea frecuentemente el pretérito compuesto. El juego entre el pretérito compuesto y el pretérito simple le sirve para acercar y alejar los acontecimientos al/del protagonista. Los dos paradigmas verbales se encuentran en oposición temporo-aspectual dentro de la esfera del presente del narrador. El pretérito compuesto sirve para expresar las acciones relacionadas con el momento del habla (pensamiento), las acciones que aún duran, continúan o son consecuencia de una acción pasada. Todo lo que el narrador siente como pasado, aunque próximo a su presente pero terminado, está en pretérito simple.

El niño recuerda la cara del muerto, la ha retenido y la ve. Pero el abuelo regresó, hace un momento, del cuarto vecino, rodó la silla, se ha sentado junto a su madre y ahora sigue sentado. Los hombres han dejado de fumar y ahora no fuman (LH 45).

Ahora el ataúd está cerrado, pero yo recuerdo la cara del muerto. La he retenido con tanta precisión que si miro hacia la pared yeo los ojos abiertos, las mejillas estiradas y grises como la tierra húmeda, la lengua mordida a un lado de la boca. Esto me produce una ardorosa sensación de intranquilidad. Tal vez el pantalón no deje de apretarme nunca a un lado de la pierna.

Mi abuelo se ha sentado junto a mi madre. Cuando regresó del cuarto vecino rodó la silla y ahora permanece aquí. sentado junto a ella, sin decir nada, la barba apoyada en el bastón y estirada hacia adelante la pierna coja. Mi abuelo espera. Mi madre, como él, espera. Los hombres que han dejado de fumar en la cama y permanecen quietos, ordenados, sin mirar el ataúd, ellos también esperan. ( $L H, 45)$

El niño observa cómo el abuelo se mueve en la habitación, recoge objetos, los coloca en el ataúd. Estas acciones se desenvuelven ante los ojos del niño y coinciden con el momento del monólogo. No se presentan como acciones terminadas sino como acciones que aún continúan y se indican con el pretérito compuesto (ha estado moviéndose, ha recogido, ha colocado, he vuelto a mirar) y con la perífrasis verbal estar + gerundio en el presente (está echando). (LH 11-12)

Mi abuelo ha estado moviéndose en la habitación. Ha recogido algunos objetos y los ha colocado en la caja. He vuelto a mirar a mamá con la esperanza que me diga, por qué mi abuelo está echando cosas en el ataúd. Pero mi madre parece imperturbable dentro del traje negro, y parece esforzarse por no mirar hacia el lugar donde está el muerto. Yo también quiero hacerlo, pero no puedo. Lo miro fijamente, lo examino. (LH, 11-12). 
Las acciones pasadas terminadas en un pasado reciente (acentuado con indicadores de tiempo reciente: hoy, hace un momento, ahora) o alejado se indican con el pretérito simple y el pluscuamperfecto (LH 10, LH 13, LH 82).

No sé por qué me han traído. Nunca había entrado en esta casa y hasta creí que estaba deshabitada. Es una casa grande, en esquina, cuyas puertas, creo, no han sido abiertas nunca. Siempre creí que la casa estaba desocupada. Sólo ahora, después de que mamá me dijo: "Esta tarde no irás a la escuela", y yo no sentí alegría porque me lo dijo con la voz grave y reservada; y la vi regresar con mi vestido de pana y me lo puso sin hablar y salimos a la puerta a juntarnos con mi abuelo; y caminamos las tres casas que separan ésta de la nuestra, sólo ahora me he dado cuenta de que alguien vivía en esta esquina. Alguien que ha muerto y que debe ser el hombre a quiense refirió mi madre cuando dijo: "Tienes que estar muy juicioso en el entierro del doctor." $(\mathrm{LH}, 10)$

Tal vez por eso he traído al niño. Cuando papá me dijo hace un momento: "Tiene que acompañarme", lo primero que se me ocurrió fue traer también al niño para sentirme protegida. Ahora estamos aqui, en esta sofocante tarde de septiembre, sintiendo que las cosas que nos rodean son los agentes despiadados de nuestros enemigos. ( $L H, 13)$

Creí que esa tarde se había reconciliado en el recuerdo, asi que hoy le dije a mi mujer que se vistiera de negro para acompañarme. Pero el juguete está otra vez en el cajón. La música ha perdido su efecto. Adelaida está ahora aniquilándose. Está triste y devastada, y se pasa horas enteras rezando en el cuarto. "Sólo a ti se te podía ocurrir hacer ese entierro", me diio. "Después de todas las desgracias que han caído sobre nosotros, lo único que nos faltaba era ese maldito año bisiesto. $Y$ después el diluvio". Traté de persuadirla de que tenía mi palabra de honor comprometida en esta empresa. (LH, 82)

Los pensamientos de los protagonistas se vuelven hacia el pasado. A veces un factor externo desencadena la memoria. El pito del tren no provoca solamente pensamientos sobre el presente de Macondo, sobre lo que la gente está haciendo en aquel preciso momento sino también evoca eventos pasados. El niño recuerda a sus compañeros de clase y al amigo Abraham, Isabel y el coronel recuerdan lo que ocurrió hace veinticinco años en Macondo. Lo que sucede en el pueblo en el momento del monólogo interior se expresa con los paradigmas verbales de la serie básica, ya que se trata de acciones que coinciden con el presente del narrador (LH 12, LH 14-15), los recuerdos de los tiempos de antaño figuran en los paradigmas de la serie del pasado (LH 15, LH 20, LH 37).

Vuelve a pitar el tren cada vez más distante, y pienso de repente: "Son las dos y media". $Y$ recuerdo que a esta hora (mientras el tren pita en la última vuelta del pueblo) los muchachos están haciendo fila en la escuela para asisitir a la primera clase de la tarde. (LH, 12)

Oigo pitar el tren en la última vuelta. "Son las dos y media", pienso; y no puedo sortear la idea de que a esta hora todo Macondo está pendiente de lo que hacemos en esta casa. Pienso en la señora Rebeca, flaca y apergaminada, con algo de fantasma doméstico en el mirar y el vestir, sentada junto al ventilador eléctrico (...)

No puedo abandonar esta idea. No pensar que son las dos y media; que pasa la mula del correo envuelta en una polvareda abrasante, seguida por los hombres que han interrumpido la siesta del miércoles para recibir el paquete de los periódicos. El padre Angel, sentado, duerme en la sacristía, con un breviario abierto sobre el vientre grasoso (...) (LH, 14-15) 
Ahora estaría yo en la casa, tranquila, si hace veinticinco años no hubiera llegado este hombre donde mi padre con una carta de recomendación que nadie supo de dónde vino y se hubiera. quedado entre nosotros, alimentándose de hierba y mirando a las mujeres con esos codiciosos ojos de perro que le han saltado de las órbitas. $(\mathrm{LH}, 15)$

Los hombres traen el ataúd y bajan el cadáver. Entonces recuerdo el día de hace veinticinco años en que llegó a mi casa y me entregó la carta de recomendación, fechada en Panamá y dirigida a mí por el Intendente General del Litoral Atlántico a fines de la guerra grande, el coronel Aureliano Buendía. (LH, 20).

Tobias, Abraham, Gilberto y yo abandonamos la escuela ayer a esa hora, y fuimos a las plantaciones con una honda, un sombrero grande para echar pájaros y una navaja nueva. ( $L H$, 37)

Los dos paradigmas verbales de la serie del pasado: el pretérito simple y el imperfecto se encuentran en oposición aspectual. Con el imperfecto las acciones se presentan en perspectiva cursiva, con el pretérito simple en perspectiva global. Con el imperfecto se pinta el fondo, el segundo plano, dentro del cual se desenvuelven acciones del primer plano que figuran en pretérito simple (LH 32).

Cuando se anunció la llegada del nuevo párroco, en 1903, la mujer seguía viviendo en el cuarto con el niño. Media población salió al camino real a esperar la llegada del sacerdote. La banda rural estuvo tocando piezas sentimentales hasta cuando vino un muchacho, jadeante, reventando, a decir que la mula del párroco estaba en la última vuelta del camino. Entonces los músicos cambiaron de posición e iniciaron una marcha. $(\mathrm{LH}, 32)$

Con el imperfecto se indica la simultaneidad en relación a otras acciones perfectivas o imperfectivas (LH 34, LH 38).

Pero estaba dando vueltas en la oficina cuando llegué y le dije buenas tardes, y él no contestó porque estaba mirando en la repisa la bailarina de cuerda. (LH, 34)

Abraham me entendió. Sólo él entiende mis palabras. "Está bien", dijo, y caminó hacia el agua a través del aire endurecido y agrio. Dijo: "Empieza a desvestirte y te esperamos en la piedra". $Y$ lo dijo mientras se zambullía y volvía a salir reluciente como un pez plateado y enorme, como si el agua se hubiera vuelto líquida a su contacto. $(L H, 38)$

Con el imperfecto se describen las características de los lugares, personas y objetos (LH 31), se describen costumbres y acciones que se repiten (LH 47).

Detrás del templo, al otro lado de la calle, había un patio sin árboles. Eso era a fines del siglo pasado, cuando llegamos a Macondo y aún no se había iniciado la construcción del templo. Eran terrones pelados, secos, donde jugaban los niños al salir de la escuela. $(L H, 31)$

Al principio dormía hasta las siete. Se le veía aparecer en la cocina, con la camisa sin cuello abotonada hasta arriba, enrolladas hasta los codos las mangas arrugadas y sucias, los escuálidos pantalones a la altura del pecho y el cinturón amarrado por fuera, mucho más abajo de la pretina. Se tenía la impresión de que los pantalones iban a resbalar a caer, por falta de un cuerpo sólido en qué sostenerse. No había enflaquecido, pero en su rostro se advertía no ya el gesto militar y altanero del primer año, sino la expresión abúlica y fatigada del hombre que no sabe qué será de su vida un minuto después, ni tiene el menor interés de averiguarlo. Tomaba su 
café negro, a las siete pasadas, y regresaba después al cuarto, repartiendo al regreso sus inexpresivos buenos días. $(\mathrm{LH}, 47)$

Una técnica narrativa usada con frecuencia en La Hojarasca es la técnica de la caja china descrita por Vargas Llosa (1971, p. 287); se trata de un relato dentro del relato presentado en discurso indirecto o directo con el verbo introductorio en pretérito simple (perspectiva global) o imperfecto (perspectiva cursiva). Isabel narra la historia de Meme y recuerda cómo Meme se acordaba de su madre y cómo se acordó de ella en aquella noche (LH 26-27).

Meme estaba derecha y sombría, hablando de aquel pintoresco esplendor feudal de nuestra familia en los últimos años del siglo anterior, antes de la guerra grande. Meme recordaba a mi madre: La recordó esa noche en que yo venía de la iglesia y me dijo con su airecillo burlón y un poco irónico: "Chabela te vas a casar y no me habías dicho nada". Eso fue precisamente en los días en que yo había deseado a mi madre y procuraba regresarla con mayor fuerza a mi memoria. "Era el vivo retrato tuyo", diio. Y yo lo creía realmente. Yo estaba sentada frente a la india que hablaba con un acento mezclado de precisión y vaguedad (...) Me habló del viaje de mis padres durante la guerra, de la áspera peregrinación que habria que concluir con el establecimiento en Macondo. Mis padres huian de los azares de la guerra y buscaban un recodo próspero y tranquilo dónde sentar sus reales y oyeron hablar del becerro de oro y vinieron a buscarlo en lo que entonces era un pueblo en formación, fundado por varias familias refugiadas, cuyos miembros se esmeraban tanto en la conservación de sus tradiciones y en las prácticas religiosas como en el engorde de sus cerdos. Macondo fue para mis padres la tierra prometida, la paz y el Vellocino. (LH, 26-27)

También Adelaida, la madrastra de Isabel, habla a través de su boca (LH 57, LH 58). Los verbos introductorios en LH 57 están en perspectiva global cuando Adelaida introduce en el relato otras personas, y en perspectiva cursiva cuando es Isabel la que usa el verbo introductorio para presentar lo dicho por Adelaida. Hay varias voces (Isabel, Adelaida, el coronel, Meme). Isabel evocó la imagen de su madrastra, cuando estaban sentadas entre las flores y cosían el vestido de bodas, por eso los verbos que introducen el relato de Adelaida están en imperfecto, las acciones se presentan en curso. Los relatos dentro del relato de Adelaida están en perspectiva global, presentadas como acciones pasadas terminadas.

Mi madrastra hablaba, sin dejar de coser símbolos, bordando laberintos blancos. Decía: "Esa noche estábamos sentados a la mesa (todos menos él, porque desde la tarde en que regresó por última vez de la peluquería no hacía la comida de la tarde) cuando Meme vino a servirnos. Estaba demudada. "¿Qué te pasa Meme?", le dije. Nada señora. ¿Por qué? Pero nosotros sabíamos que no estaba bien, porque vacilaba junto a la lámpara y toda ella tenía un aspecto enfermizo. "Por Dios, Meme, que tú no estás bien", dije. Y ella se sostenía a medias, como le era posible, hasta cuando se dio vuelta hacia la cocina con la bandeja. Entonces tu padre que la observaba durante todo el tiempo, le dijo: "Si no se siente bien, que se acueste". Y ella no dijo nada. $(\mathrm{LH}, 57)$

En LH 58, cuando la madrastra se dirige a Isabel, el verbo introductorio está en imperfecto (decía), cuando habla el padre a la madrastra, el verbo introductorio está en pretérito simple (dijo). El cambio de relato se refleja en el cambo del paradigma. 
Entonces fue cuando tu padre fue a buscarlo a ese aposento para que atendiera a Meme.

En ocho años que llevaba de estar en nuestra casa - decía mi madrastra - nunca habíamos solicitado sus servicios para nada grave. Las mujeres fuimos al cuarto de Meme, la friccionamos con alcohol, y aguardamos a que volviera tu padre. Pero no vinieron, Isabel.(...)

Sólo a medianoche llegó tu padre, decía. Dijo flojamente: "Que le den fricciones de alcohol, pero que no la purguen". ( $L H, 58)$

\section{Cien años de Soledad}

La novela Cien años de soledad crea un mundo ficticio total en su contenido y en su forma. Cien años de soledad son cien años de la familia Buendía y del pueblo de Macondo. Todos los relatos de Macondo y de los Buendía, sembrados por otras novelas y cuentos escritos antes de Cien años de soledad, encuentran su sentido y su conclusión en la novela. ${ }^{6} \mathrm{El}$ mundo que crea García Márquez se infla, se hincha, se reproduce. El juego con el tiempo y el lugar, los destinos entretejidos de innombrables protagonistas, la invasión de lo maravilloso y lo fantástico en la vida cotidiana acompañan al lector asombrado desde el comienzo hasta el final cuando termina la saga de Macondo y de la familia Buendía, cuando uno y otro desaparecen de la faz de la Tierra y siguen viviendo como mito.

"Cien años de soledad" es una novela total sobre todo porque pone en práctica el utópico designio de todo suplantador de Dios: describir una realidad total, enfrentar a la realidad real una imagen que es su expresión y negación. Esta noción de totalidad, tan escurridiza y compleja, pero tan inseparable de la vocación del novelista, no sólo define la grandeza de "Cien años de soledad": da también su clave. Se trata de una novela total por su materia, en la medida que describe un mundo cerrado, desde su nacimeinto hasta su muerte y en todos los órdenes que lo componen - el individual y el colectivo, el legendario y el histórico, el cotidiano y el mítico-, y por su forma, ya que la escritura y la estructura tienen, como la materia que cuaja en ellas, una naturaleza exclusiva, irrepetible y autosuficiente. (Vargas Llosa, 1971, p. 480)

La primera frase ${ }^{7}$ de Cien años de soledad anuncia un narrador omnisciente que narra la historia de Macondo y de los Buendía en tercera persona singular. Es invisible, observa los acontecimientos desde fuera y los presenta globalmente. Ya que conoce el curso de los eventos, juega con el tiempo, pasea a sus anchas por la novela, se asoma al futuro, mira el pasado o sigue linealmente el desarrollo de la acción. El narrador se

6 Los protagonistas y los temas de los cuentos y novelas anteriores aparecen en Cien años de soledad. Algunos relatos comenzados en las obras anteriores concluyen en la novela, otros se mencionan brevemente. En Cien años de soledad deambulan protagonistas de La Hojarasca, La Mala Hora, Los Funerales de la Mamá Grande. Escenas y relatos de El coronel no tiene quien le escriba, Isabel viendo llover en Macondo, Un día después del sábado, Rosas Artificiales, etc. aparecen en Cien años de soledad.

7 Como en La Hojarasca también en Cien años de soledad la primera frase es primordial:

- ¿Cuál fue para ti el momento más difícil de la novela?

- Empezar. Recuerdo muy bien el día en que terminé con mucha dificultad la primera frase, y me pregunté aterrorizado qué carajo vendría después. (Gabriel García Márquez, 1983, p. 80). 
sirve a menudo de las técnicas del flash back y del flash forward. La primera frase es un flash forward que proyecta los acontecimientos hacia adelante en el tiempo (el momento del fusilamiento), seguido de un flash back cuando el protagonista recuerda su vida pasada (el momento cuando el padre llevó a Aureliano Buendía a conocer el hielo) y los inicios de Macondo. Desde allí el relato sigue el orden cronológico lineal natural hasta alcanzar el momento de encontrarse Aureliano Buendía frente el pelotón de fusilamiento ("muchas páginas después", en la página 107).

El narrador, a primera vista omnisciente, se transforma en el narrador protagonista. El lector lo descubre en el último párrafo de la novela. El narrador oculto es en realidad Aureliano Babilonia quien está leyendo los manuscritos proféticos de Melquíades. Aureliano se da cuenta de que está leyendo lo que está viviendo y que experimenta los últimos instantes de su vida y de la vida de Macondo. ${ }^{8}$

Sin embargo, antes de llegar al verso final ya había comprendido que no saldría jamás de ese cuarto, pues estaba previsto que la ciudad de los espejos (o los espejismos) sería arrasada por el viento y desterrada de la memoria de los hombres en el instante en el que Aureliano Babilonia acabara de descifrar los pergaminos, y que todo lo escrito en ellos era irrepetible desde siempre y para siempre, porque las estirpes condenadas a cien años de soledad no tenían una segunda oportunidad sobre la tierra. (CAS, 325)

Además del cambio del punto de mira del narrador (narrador omnisciente narrador protagonista) arriba descrito existe en la novela otro cambio en la perspectiva del narrador. Se trata del monólogo interior de Fernanda Carpio, un relato dentro de la narración del narrador principal. La cantaleta de Fernanda está en discurso indirecto libre. Los paradigmas verbales pertenecen casi todos a la serie de paradigmas del pasado. Las descripciones de su vida en Macondo, las acciones habituales o reiterativas están en imperfecto, en perspectiva cursiva. El pretérito simple y el pluscuamperfecto indican acciones pasadas y terminadas de su vida en perspectiva global. Los paradigmas de la serie básica (imagínese, válgame Dios, bendito sea Dios, que en paz descanse) interrumpen la narración y señalan el cambio de la perspectiva del narrador (del narrador omnisciente a Fernanda, narrador protagonista).

Aureliano Segundo no tuvo conciencia de la cantaleta hasta el día siguiente, después del desayuno, cuando se sintió aturdido por un abejorreo que era entonces más fluido y alto que el rumor de la lluvia, y era Fernanda que se paseaba por toda la casa doliéndose de que la hubieran educado como una reina para terminar de sirvienta en una casa de locos, con un marido holgazán, idólatra, libertino, que se acostaba bocarriba a esperar que le llovieran panes del cielo, mientras ella se destroncaba los riñones tratando de mantener a flote un hogar emparapetado con alfileres, donde había tanto que hacer, tanto que soportar y corregir desde que amanecía Dios hasta la hora de acostarse, que llegaba a la cama los ojos llenos de polvo de

8 Así, al final, sabemos que el narrador era pieza integrante de la realidad ficticia, es decir, alguien (algo: los manuscritos) que va a desaparecer con Macondo, que va a ser destruido junto con lo narrado. La profecia de Melquiades y sus manuscritos no han sido forjados en una exterioridad sino en el seno mismo de la realidad ficticia. En el instante en que el narrador y lo narrado coinciden, ambos desaparecen. (Vargas Llosa, op. cit., p. 541). 
vidrio y, sin embargo, nadie le había dicho nunca buenos días, Fernanda, qué tal noche pasaste, Fernanda, ni le habían preguntado aunque fuera por cortesía por qué estaba tan pálida ni por qué despertaba con esas ojeras de violeta, a pesar de que ella no esperaba, por supuesto, que aquello saliera del resto de una familia que al fin y al cabo la habia tenido siempre como un estorbo, como el trapito de bajar la olla, como un monigote pintado en la pared, y que siempre andaban desbarrando contra ella por los rincones llamándola santurrona, llamándola farisea, llamándola lagarta, y hasta Amaranta, que en paz descanse, había dicho de viva voz de que ella era de las que confundían el recto con las témporas, bendito sea Dios, qué palabras, y ella había aguantado todo con resignación por las intenciones del Santo Padre, pero no había podido soportar más cuando el malvado de José Arcadio Segundo dijo que la perdición de la familia habia sido abrirle las puertas a una cachaca, imagínese una cachaca mandona, válgame Dios, una cachaca hija de mala saliva, de la misma índole de los cachacos que mandó el gobierno a matar trabajadores, digame usted, y se refería a nadie menos que a ella, la ahijada del Duque de Alba, una dama con tanta alcurnia que le revolvía el hígado a las esposas de los presidentes, una fijodalga de sangre como ella que tenía derecho a firmar con once apellidos peninsulares, y que era el único mortal en ese pueblo de bastardos que no se sentía emberenejado frente a dieciséis cubiertos, para que luego el adúltero de su marido dijera muerto de risa que tantas cucharas y tenedores, y tantos cuchillos y cucharitas no eracosa de cristianos, sino de ciempiés, y la única que podía determinar a ojos cerrados cuándo se servía el vino rojo, y de qué lado y en qué copa, y no como la montuna de Amaranta, que en paz descanse, que creía que el vino blanco se servía de día y el vino rojo de noche, y la única en todo el litoral que podía vanagloriarse de no haber hecho del cuerpo sino en bacinillas de oro, para que luego el coronel Aureliano Buendía, que en paz descanse, tuviera el atrevimiento de preguntar con su mala bilis de masón de dónde había merecido ese privilegio, si era que ella no cagaba mierda, sino astromelias, imagínese, con esas palabras, y para Renata, su propia hija, que por indiscreción había visto sus aguas mayores en el dormitorio, contestara que de verdad la bacinilla era de mucho oro y de mucha heráldica, pero lo que tenía dentro era pura mierda, mierda fisica, y peor todavía que las otras porque era mierda de cachaca, imagínese, su propia hija, de modo que nunca se había hecho ilusiones con el resto de la familia, pero de todos modos tenía derecho a esperar un poco de más consideración de parte de su esposo, puesto que bien o mal era su cónyuge de sacramento, su autor, su legítimo perjudicador, que se echó encima por voluntad libre y soberana la grave responsabilidad de sacarla del solar paterno, donde nunca se privó ni se dolió de nada, donde tejía palmas fúnebres por gusto de entretenimiento, puesto que su padrino habia mandado una carta con su firma y el sello de su anillo impreso en el lacre, sólo para decir que las manos de su ahijada no estaban hechas para menesteres de este mundo, como no fuera tocar el clavicordio y, sin embrago, el insensato de su marido la había sacado de su casa con todas las admoniciones y advertencias y la había llevado a aquella paila de infierno donde no se podía respirar de calor, y antes de que ella acabara de guardar sus dietas de Pentecostés ya se había ido con sus baúles trashumantes y su acordeón de perdulario a holgar en adulterio con una desdichada a quien bastaba con verle menear las nalgas, bueno ya estaba dicho, a quien bastaba con verle menear las nalgas de potranca para adivinar que era una, que erg una, todo lo contrario de ella, que era una dama en el palacio o en la pocilga, en la mesa o en la cama, una dama de nación, temerosa de Dios, obediente de sus leyes y sumisa a sus designios, y con quien no podía hacer, por supuesto, las maromas y vagabundinas que hacía con la otra, que por supuesto se prestaba a todo, como las matronas francesas, y peor aún, pensándolo bien, porque éstas al menos tenian la honradez de poner un foco colorado en su puerta, semejantes porquerias, imagínese ni más faltaba, con la hija única y bienamada de doña Renata Argote y don Fernando del Carpio, y sobre todo de éste, por supuesto, un santo varón, un cristiano de los grandes, Caballero de la Orden del Santo 
Sepulcro, de esos que reciben directamente de Dios el privilegio de conservarse intactos en la tumba, con la piel tersa como raso de novia y los ojos vivos y diáfanos como las esmeraldas. (CAS, 254-256)

En este mundo total y autosuficiente también el tiempo tiene su propia evolución. Por una parte, es un tiempo cíclico que se repite a todos los niveles de la novela y crea la sensación de un mundo mítico. Por otra parte, el tiempo real es el tiempo cronológico, lineal, implacable que lleva a la destrucción final de Macondo.

Qué quería - murmuró -, el tiempo pasa.

- Así es - dijo Úrsula -, pero no tanto.

Al decirlo, tuvo conciencia de estar dando la misma réplica que recibió del coronel Aureliano Buendía en su celda de sentenciado, y una vez más se estremeció con la comprobación de que el tiempo no pasaba, como ella lo acababa de admitir, sino que daba vueltas en redondo. (CAS, 263-264)

No había ningún misterio en el corazón de un Buendía que fuera impenetrable para ella, porque un siglo de naipes y de experiencias le había enseñado que la historia de la familia era un engranaje de repeticiones irreparables, una rueda giratoria que hubiera seguido dando vueltas hasta la eternidad, de no haber sido por el desgaste progresivo e irremediable del eje. (CAS, 309-310)

En la novela Cien años de soledad el autor usa algunas perífrasis verbales como indicadores de valores aspectuales y temporales. La más sobresaliente es la perífrasis verbal haber $d e+$ inf. que aparece en la primera frase de la novela y se repite lo largo de la novela. Con ella se señalan el valor temporal de posterioridad y el valor aspectual de inminencia de la acción. Además su valor predominante es el valor modal de obligación que en conjunción de los ya mencionados confiere un matiz de fatalidad, de algo ineludible, obligativo para el futuro. Por eso, en este estudio, la denomino perifrasis nefasta.

Muchos años después, frente al pelotón de fusilamiento, el coronel Aureliano Buendía había de recordar aquella tarde remota en que su padre lo llevó a conocer el.hielo. (CAS, 9)

La perífrasis verbal de la primera frase es importantísima para entender el juego del tiempo en la novela. Es la previsión del desarrollo de los acontecimientos marcados por la fatalidad y presenta desde el primer momento el ambiente temporo-espacial cerrado de la novela. En la novela se repite como una fórmula mágica, anunciadora de eventos trágicos, inevitables, que marcaron la vida de los protagonistas.

El tren inocente amarillo que tantas incertidumbres y evidencias, y tantos halagos y desventuras y tantos cambios, calamidades y nostalgias había de llevar a Macondo. (CAS, 178)

Los acontecimientos que habian de darle el golpe mortal a Macondo empezaban a vislumbrarse cuando llevaron a la casa al hijo de Meme Buendía. (CAS, 231)

Las casas de madera, las frescas terrazas donde transcurrian las serenas tardes de naipes, parecían arrasadas por una anticipación del viento profético que años después había de borrar a Macondo de la faz de la tierra. (CAS, 260) 
Con algunos recursos narrativos especiales como son la exageración, la enumeración, la repetición, el cambio de las cualidades de los objetos, etc. el autor mezcla los fenómenos mágicos y los hechos reales. Con la enumeración de acontecimientos normales y extraños se borra el límite entre ellos y se funde lo mágico con lo real. Además de los paradigmas verbales, sobre todo la oposición pretérito simple : imperfecto, ${ }^{9}$ que desempeñan un papel primordial en la creación del ritmo de la narración, también algunas perífrasis verbales contribuyen a ello.

Las perffrasis volver a + infinitivo y soler + infinitivo expresan la reiteración y la habitud y participan en la creación de un mundo en el que las cosas, los eventos, las personas hasta los nombres se repiten. En Cien años de soledad se tiene la impresión de que todo se repite, los fenómenos se siguen en un círculo creando un mundo cerrado y fatal.

Con volver $a+$ inf. en imperfecto se señala una repetición múltiple (CAS 17), también con otros paradigmas verbales y un contexto apropiado se puede señalar la repetición múltiple (CAS 26a, CAS 219-220). Con el pretérito simple se indica que la acción se repite una sola vez. (CAS 20, CAS 26b).

No podían regresar, porque la trocha que iban abriendo a su paso se volvía a cerrar en poco tiempo, con una vegetación nueva que casi veían crecer ante sus ojos. (CAS, 17)

Dos noches después, Úrsula volvió a ver a Prudencio Aguilar en el baño, lavándose con el tapón de esparto la sangre cristalizada del cuello. Otra noche lo vio paseándose bajo la lluvia. José Arcadio Buendía, fastidiado por las alucinaciones de su mujer, salió al patio armado con la lanza. Alli estaba el muerto con su expresión triste.

- Vete al carajo - le gritó José Arcadio Buendia -. Cuantas veces regreses volveré a matarte. (CAS, 26a)

Se sentó a esperarla, como quien espera una carta, y era cierto que en una época arrancaba botones para volver a pegarlos, de modo que la ociosidad no hiciera más larga y angustiosa la espera. (CAS, 219-220)

Aquellas alucinantes sesiones quedaron de tal modo impresas en la memoria de los niños, que muchos años más tarde, un segundo antes de que el oficial de los ejércitos regulares diera la orden de fuego al pelotón de fusilamiento, el coronel Aureliano Buendia volvió a vivir la tibia tarde de marzo en que su padre interrumpió la lección de física, y se quedó fascinado, con la mano en el aire y los ojos inmóviles, oyendo a la distancia los pífanos y tambores y sonajas de los gitanos que una vez más llegaban a la aldea, pregonando el último y asombroso descubrimiento de los sabios de Memphis. (CAS, 20).

Dos noches después, Úrsula volvió a ver a Prudencio Aguilar en el baño, lavándose con el tapón de esparto la sangre cristalizada del cuello. Otra noche lo vio paseándose bajo la lluvia. José Arcadio Buendía, fastidiado por las alucinaciones de su mujer, salió al patio armado con la lanza. Allí estaba el muerto con su expresión triste. (CAS, 26b)

Con soler + infinitivo se indican acciones habituales, costumbres que se repiten a lo largo de la vida de los protagonistas (CAS 136, CAS 191, CAS 291). 
"El mejor amigo -solía decir entonces - es el que acaba de morir." (CAS, 136)

Aureliano Centeno fue encontrado en la hamaca que solía colgar en la fábrica, con un punzón de picar hielo clavado hasta la empuñadura entre las cejas. (CAS, 191)

Uno de los niños, que tenía el cabello rubio y crespo, y los ojos de vidrios rosados como los conejos, solía dormir en la casa. (CAS, 291)

La atmósfera de la duración o de la eterna repetición se indica con las perífrasis verbales seguir + ger., continuar + ger. (CAS 45, CAS 219, CAS 210, CAS 220) muy frecuentes en la novela.

Así continuaron viviendo en una realidad escurridiza, momentáneamente capturada por las palabras, pero que había de fugarse sin remedio cuando olvidaran los valores de la letra escrita. $(C A S, 45)$

Los rollos de música que ella misma había echado a la basura con el pretexto de que se estaban pudriendo con la humedad, seguían girando y golpeando martinetes en su memoria. (CAS, 219).

Desde que decidió no venderlos, seguía fabricando dos pescaditos al día, y cuando completaba veinticinco volvía a fundirlos en el crisol para empezar a hacerlos de nuevo. (CAS, 210)

Elaboró el plan con tanto odio que la estremeció la idea de que lo habría echo de igual modo si hubiera sido con amor, pero no se dejó aturdir por la confusión, sino que siguió perfeccionando los detalles tan minuciosamente que llegó a ser más que una especialista, una virtuosa en los ritos de la muerte. (CAS, 220)

Las acciones vistas en su desarrollo (perspectiva cursiva) indican la repetición, la habitud, el lento progresar. Este aspecto se acentúa aún más con la perífrasis verbal $i r(s e)+$ gerundio en imperfecto (tiene un efecto estilístico de un progresar paulatino, crea imágenes prolongadas). La perífrasis verbal $i r(s e)+$ gerundio puede señalar también la perspectiva global (el auxiliar está en pretérito simple) y expresa el progresar visto globalmente, es decir, señala una acción progresiva pero terminada.

Poco a poco, sin embargo, y a medida que la guerra se iba intensificando y extendiendo su imagen se fue borrando en un universo de irrealidad. Los puntos y rayas de su voz eran cada vez más remotos e inciertos, y se unian y combinaban para formar palabras que paulatinamente fueron perdiendo todo sentido. (CAS, 132)

En el curso de la primera semana se fue acostumbrando a los desgastes que habian hecho el tiempo y la lluvia en la salud de su concubina, y poco a poco fue viéndola como era antes (...) (CAS, 253)

Sin embargo, sus noticias se fueron haciendo poco a poce tan inciertas, y tan esporádicas y melancólicas las cartas del sabio, que Aureliano se acostumbró a pensar en ellas como Amaranta Úrsula pensaba en su marido, y ambos quedaron flotando en el universo vacío, donde la única realidad cotidiana y eterna era el amor. (CAS, 318)

Casi siempre, entre amor y amor, comían desnudos en la cama, en el calor alucinante y bajo las estrellas diurnas que el óxido iba haciendo despuntar en el techo de zinc. (CAS, 302) 
De modo que Aureliano y Amaranta Úrsula aceptaron la versión de la canastilla, no porque la creyeran sino porque les ponía a salvo de sus terrores. A medida que avanzaba el embarazose iban convirtiendo en un ser único, se integraban cada vez más en la soledad de una casa a la que sólo le hacía falta un último soplo para derrumbarse. (CAS, 320)

En Cien años de soledad prevalecen los paradigmas verbales de la serie del pasado, paradigmas de la narración por excelencia. Los paradigmas de la serie básica aparecen en los discursos intercalados en el texto narrativo (discurso directo, discurso indirecto, discurso indirecto libre). Los verbos introductorios se presentan en perspectiva cursiva (con el verbo en imperfecto) cuando se señalan acciones que se repiten (CAS 107) y en perspectiva global (con el verbo en pretérito simple) cuando se señalan acciones puntuales y terminadas (CAS 113).

Rebeca Buendía se levantaba a las tres de la madrugada desde que supo que Aureliano sería fusilado. Se quedaba en el dormitorio a oscuras, vigilando por la ventana entreabierta el muro del cementerio, mientras que la cama en que estaba sentada se estremecía con los ronquidos de José Arcadio. Esperó toda la semana con la misma obstinación recóndita con que en otra época esperaba las cartas de Pietro Crespi. "No lo fusilarán aquí", le decía José Arcadio. "Lo fusilarán a medianoche en el cuartel para que nadie sepa quién formó el pelotón, y lo enterrarán allá mismo." Rebeca siguió esperando. "Son tan brutos que lo fusilarán aquí", decía. (CAS, 107)

Una noche le preguntó al coronel Gerineldo Márquez:

- Dime una cosa, compadre: ¿por qué estás peleando?

- Por qué ha de ser, compadre - contestó el coronel Gerineldo Márquez -: por el gran partido liberal.

- Dichoso tú que lo sabes - contestó él -. Yo por mi parte, apenas ahora me doy cuenta que estoy peleando por orgullo.

- Eso es malo - dijo el coronel Gerineldo Márquez. (CAS, 113)

La oposición aspectual entre el pretérito simple y el imperfecto resalta el ritmo de la narración. Las acciones en pretérito simple (perspectiva global) aceleran la narración: son acciones concluidas que se suceden. Las acciones en imperfecto (perspectiva cursiva) la frenan, sirven para divagar por otros ambientes: descripciones, creaciones de mundos paralelos, pensamientos, sueños, etc. Dos horas antes de morir Arcadio Buendía (CAS 99-100) está pensando en su familia. La primera frase está en pretérito simple: la constatación del fusilamiento de Arcadio. Sigue un rápido flash back de dos horas. El tiempo cronológico está en pretérito simple (escuchó los cargos), pero sus reflexiones están en imperfecto: el tiempo cronológico se para, Arcadio pierde el sentido del tiempo real y se sumerge en sus pensamientos. La repetición crea la impresión de lo perpetuo. Hay un contraste entre el tiempo real, cronológico que transcurre normalmente (en pretérito simple.) y el tiempo interno de Arcadio, mucho más lento (en imperfecto.).

Al amanecer, después de un consejo de guerra sumario, Arcadio fue fusilado contra el muro del cementerio. En las dos últimas horas de su vida no logró entender por qué había desaparecido el miedo que lo atormentó desde la infancia. Impasible, sin preocuparse siquiera por demostrar su reciente valor, escuchó los interminables cargos de acusación. Pensaba en Úrsula, que a esa 
hora debía estar bajo el castaño tomando el café con José Arcadio Buendía. Pensaba en su hija de ocho meses, que aún no tenía nombre, y en el que iba a nacer en agosto. Pensaba en Santa Sofia de la Piedad, a quien la noche anterior dejó salando un venado para el almuerzo del sábado, y añoró su cabello chorreando sobre los hombros y sus pestañas que parecían artificiales. Rensaba en su gente sin sentimentalismos, en un severo ajuste de cuentas con la vida, empezando a comprender cuânto quería en realidad a las personas que más había odiado. El presidente del consejo de guerra inició su discurso final, antes de que Arcadio cayera en la cuenta de que habian transcurrido dos horas. (CAS, 99-100)

En la primera frase de la novela en el momento en que el narrador se vuelve hacia el pasado (el padre lleva a Aureliano a conocer el hielo y Aureliano recuerda la vida en Macondo de aquel entonces) la narración sigue la línea cronológica normal (CAS 9). La descripción de Macondo, la creación de un marco a los acontecimientos, las acciones que se repiten regularmente se encuentran en imperfecto (perspectiva cursiva). Algunos acontecimientos (llevó, llevaron) están enfocados con la perspectiva global (pretérito simple), son acciones instantáneas o acciones terminadas vistas en su totalidad.

Muchos años después, frente al pelotón de fusilamiento, el coronel Aureliano Buendía había de recordar aquella tarde remota en que su padre lo llevó a conocer el hielo. Macondo era entonces una aldea de veinte casas de barro y cañabrava construidas a la orilla de un río de aguas diafanas que se precipitaban por un lecho de piedras pulidas, blancas y enormes como huevos prehistóricos. El mundo era tan reciente, que muchas cosas carecian de nombre, y para mencionarlas había que señalarlas con el dedo. Todos los años, por el mes de marzo, una familia de gitanos desarrapados plantaba su carpa cerca de la aldea, y con un grande alboroto de pitos y timbalas daban a conocer los nuevos inventos. Primero llevaron el imán. (CAS, 9)

La oposición imperfecto : pretérito simple sirve también para dar relieve, para crear en el relato matices claro-oscuros (primeros y segundos planos). El segundo plano (imperfecto) es el telón de fondo para las acciones del primer plano (pretérito simple). (CAS 126, CAS 167-168)

Carmelita Montiel, una virgen de veinte años, acababa de bañarse con agua de azahares y estaba regando hojas de romero en la cama de Pilar Ternera, cuando sonó el disparo. (CAS, 126)

Se extravió por desfiladeros de niebla, por tiempos reservados al olvido, por laberintos de desilusión. Atravesó un páramo amarillo donde el eco repetía los pensamientos y la ansiedad provocaba espejismos premonitorios. Al cabo de semanas estériles, llegó a una ciudad desconocida donde todas las campanas tocaban a muerto. (CAS, 167-168).

El pretérito simple y el imperfecto también se usan en las repeticiones y enumeraciones, técnicas muy frecuentes en las obras de García Márquez. La enumeración de acciones en pretérito simple aumenta la tensión y acelera la narración (CAS 11, CAS 167, CAS 174).

Lo envió a las autoridades acompañado de numerosos testimonios sobre sus experiencias y de varios pliegos de dibujos explicativos, al cuidado de un mensajero que atravesó la sierra, se extravió en pantanos desmesurados, remontó ríos tormentosos y estuvo a punto de perecer bajo 
el azote de las fieras, la desesperación y la peste, antes de conseguir una ruta de enlace con las mulas del correo. (CAS, 11)

Con la temeridad atroz con que José Arcadio Buendía atraversó la sierra para fundar a Macondo, con el orgullo ciego con que el coronel Aureliano Buendía promovió las guerras inútiles, con la tenacidad insensata con que Úrsula aseguró la supervivencia de la estirpe, así buscó Aureliano Segundo a Fernanda, sin un solo instante de desaliento. (CAS, 167)

Hicieron añicos media vajilla, destrozaron los rosales persiguiendo a un toro para mantearlo, mataron las gallinas a tiros, obligaron a bailar a Amaranta los valses tristes de Pietro Crespi, consiguieron que Remedios, la bella, se pusiera unos pantalones de hombre para subirse a la cucaña, y soltaron en el comedor un cerdo embadurnado de sebo. (CAS, 174)

La repetición del verbo pensar en imperfecto (CAS 176) acentúa la obsesión y el odio de Amaranta por Rebeca.

Pensaba en ella al amanecer, cuando el hielo del corazón la despertaba en la cama solitaria, y pensaba en ella cuando se jabonaba los senos marchitos y el vientre macilento, y cuando se ponía los blancos pollerines y corpiños de olán de la vejez, y cuando se cambiaba en la mano la venda negra de la terrible expiación. Siempre, a toda hora, dormida y despierta, en los instantes más sublimes y en los más abyectos, Amaranta pensaba en Rebeca (...). (CAS, 176)

La repetición del verbo repicar en imperfecto acentúa el repicar largo y persistente del teléfono (CAS 301).

Trató de reconstruir con la imaginación el arrasado esplandor de la antigua ciudad de la compañia bananera, cuya piscina seca estaba llena hasta los bordes de podridos zapatos de hombre y zapatillas de mujer, y en cuyas casas desbaratadas por la cizaña encontró el esqueleto de un perro alemán todavía atado a una argolla con una cadena de acero, y un teléfono que repicaba repicaba repicaba, hasta que él lo descolgó, entendió lo que una mujer angustiada y remota preguntaba en inglés, y le contestó que sí, que la huelga había terminado, que los tres mil muertos habian sido echados al mar, que la compañia bananera se habia ido, y que Macondo estaba por fin en paz desde hacía muchos años. (CAS, 301)

\section{Conclusión}

El análisis de algunos paradigmas verbales (pretérito simple, pretérito compuesto, imperfecto) y de algunas perífrasis verbales en dos textos narrativos de Gabriel García Márquez (La Hojarasca y Cien años de soledad) corrobora la importancia de los valores aspectuales y temporales que se señalan con estos recursos lingüísticos para la creación de efectos estilísticos especiales y la construcción de un mundo ficticio propio con sus dimensiones espaciales y temporales. Este estudio contribuye a elucidar los problemas de la expresión aspectual y temporal en los textos narrativos en español y a profundizar sobre las características estilísticas de Gabriel García Márquez. 


\section{Bibliografía}

GARCÍA MÁRQUEZ, G. (1983), Conversaciones con Plinio Apuleyo Mendoza. El olor de la guayaba. Bogotá: Editorial La Oveja Negra.

GÓMEZ T., L. (1970), La estilistica en las perífrasis verbales. Homenaje universitario a Dámaso Alonso. Madrid: Gredos. 85 - 96.

GÓMEZ TORREGO, L. (1988), Perífrasis verbales. Sintaxis, semántica y estilística. Madrid: Arco/Libros.

MARKIČ, J. (1997), Aspektualne vrednosti v sodobni ameriški španščini v delih kolumbijskega pisatelja Gabriela Garcíe Márqueza. Tesis doctoral inedita. Universidad de Ljubljana, Facultad de Filosofía.

MIKLIČ, T. (1983), Lopposizione italiana perfetto vs imperfetto e lopposizione slovena dovršnost vs nedovršnost nella verbalizzazione delle azioni passate. Linguistica XXIII. Ljubljana: Filozofska fakulteta. 53-123.

MIKLIČ, T. (1994/I), Besedilni mehanizmi učasovljanja zunajjezikovnih situacij. Uporabno jezikoslovje 2 (2). Ljubljana. 80-99.

MIKLIČ, T. (1994/II), Segnalazione della temporalità nel testo: che cosa aiuta il ricevente a collocare le azioni sullasse temporale. Atti del Terzo Convegno S.I.L.F.I. Perugia. (Hrsg. L. Agostiniani).

REYES, G. (1990/I), Tiempo, modo, aspecto e intertextualidad. Revista Española de Lingüística - año 20, fasc.1: 17-53.

REYES, G. (1990/II), Valores estilísticos del imperfecto. Revista de Filología Española, tomo LXX, fasc. 1-2. Madrid: CSIC. 45-70.

SKUBIC, M. (1969), Pretérito simple y compuesto en los primeros textos castellanos. Actas del XI Congreso Internacional de Linguística y Filología Románica. Madrid: C.S.I.C. 1891-1901.

SKUBIC, M. (1978), Sur les valeurs du temps du passé dans les langues romanes. Linguistica, XVII. Ljubljana: Filozofska fakulteta. 143-159.

VARGAS LLOSA, M. (1971), Garcia Márquez: Historia de un deicidio. BarcelonaCaracas: Monte Avila Editores, C.A.

CORPUS:

GARCÍA MÁRQUEZ, G. (1985), La Hojarasca. Bogotá: Editorial La Oveja Negra. (LH)

GARCÍA MÁRQUEZ, G. (1986), Cien años de soledad, Bogotá: Editorial La Oveja Negra (CAS)

Povzetek

ČASOVNE IN ASPEKTUALNE PERSPEKTIVE V PRIPOVEDNIH DELIH

GABRIELA GARCÍE MÁRQUEZA

Prispevek se ukvarja $\mathrm{z}$ nekaterimi jezikovnimi sredstvi, ki signalizirajo časovne in aspektualne vrednosti $\mathrm{v}$ španskem jeziku v dveh romanih kolumbijskega pisatelja Gabriela Garcíe Márqueza: v njegovem zgodnjem romanu La Hojarasca (Smetje) ${ }^{10}$ in v njegovem najbolj znanem romanu Cien años de soledad (Sto let samote).

10 V slovenskem prevodu Odvrženi (Pomurska založba, 1982). 
Izsledki analiz opozicij glagolskih paradigem enostavni preterit : sestavljeni preterit in enostavni preterit : imperfekt ter nekaterih najbolj značilnih glagolskih perifraz, kažejo na bogate možnosti izražanja časa in aspekta $v$ pripovedih in ustvarjanja fiktivnega sveta $\mathrm{z}$ lastnimi časovnimi in prostorskimi odnosi. V prvem delu članka je prikazan teoretični pristop $\mathrm{k}$ proučevanju omenjenih glagolskih paradigem in perifraz. Drugi in tretji del pa sta posvečena analizi teh oblik v naravnem okolju širšega besedila. Pri proučevanju teh jezikovnih sredstev se upoštevajo nekatere pripovedne tehnike, umestitev drugih diskurzov $\mathrm{v}$ besedilo in sprememba perspektive pripovedovalca. Analiza je prispevek k proučevanju aspektualnosti in temporalnosti v sodobnem španskem jeziku in k proučevanju slogovnih značilnosti pisanja Garcíe Márqueza. 